\title{
Identitetspolitikk til besvær - om det nye ubehaget i profesjonsutøvelsen
}


Den moderne profesjonsutøveren synes å ha pådratt seg noen nye utfordringer med hensyn til forvaltning av egen myndighet som ikke var på langt nær like påtakelig bare for få tiår siden. Det er snakk om en form for ubehag eller en frykt som er knyttet til faren for å krenke andre menneskers identitetsfølelse og kanskje utløse aggresjon. Det som skrives i dette lille essayet berører spørsmål som gjelder sammenhenger mellom identitetspolitikk og myndighetsutøvelse i samfunnet. Det som skrives kan også leses som en personlig reorientering med hensyn til spørsmål som gjelder identitet. En fordums begeistring over menneskers innsats når det gjelder å presisere og polere sine identiteter har blitt erstattet av en form for besinnelse og ettertanke.

\section{Angst for oppdragelse}

For noen år siden ble det utgitt en bok med tittelen «Angsten for oppdragelse» (2012). Forfatterne Bjørn Foros og Arne Johan Vetlesen hevder at foreldre og læreres selvtillit til à være normative og tydelige overfor barn og unge i spørsmål om rett og galt er svekket. Vi som er oppdragere har blitt utydelige i våre holdninger og forlegne i våre voksenroller, skriver de. Lærere ser ut til å nøye seg med en pedagogikk for hvordan noe skal gjøres, og unngår de mer kontroversielle spørsmålet om hva som skal og bør gjøres. Elevene har på sin side blitt vant til at lærestoffet er forhåndstilpasset deres horisont og som en følge av dette utvikler de en fremmedhetsaversjon; de vil ikke høre noe som ikke allerede er innenfor forståelseshorisonten deres, skriver Foros og Vetlesen.

Foreldre og andre oppdragere i samfunnet sliter. Profesjonsutøvere, foruten lærere også politi, leger, sykepleiere, sosionomer med flere har oppgaver som i større eller mindre grad innebærer å normere folks atferd og holdninger. Blant disse profesjonsgruppene rapporteres det om ubehag forbundet med det å skulle peke på rett og galt, gi klare råd om livsstil og livsvalg osv. Den britiske psykiateren Theodor Dalrymple forteller i boka Life at The Bottom (2001) hvordan han sliter med å forvalte sin faglige autoritet i møte med pasienter fra de lavere sosiale lag i Storbritannia. Pasientene avviser svært ofte rådene til legen og ser på legens forsøk på autoritetsutøvelse som en fornærmelse. Dalrymple mener at pasientene har adoptert en rådende kulturrelativistisk tenkemåte i samfunnet og skriver at endatil slumbeboeren er aggressivt overbevist om at egen kunnskap og forståelse er tilstrekkelig og like mye verdt som legens. Væpnet med moralsk kulturrelativisme og stoltheten over egen identitet angripes og avvises profesjonsutøverens råd.

Myndighetsutøvelse i samfunnet er ifølge Foros og Vetlesen forbundet med angst og forlegenhet. Profesjonsutøvere kan imidlertid ikke fri seg fra kravet om å utøve en viss myndighet, de forvalter nemlig samfunnets institusjonaliserte oppdragervirksomhet. De er nødt til å drive opplysning og grensesetting, og de vil følgelig øve et normativt trykk som lett kan kollidere med individuell orientering og identitet. Leger har for eksempel plikt til å utfordre religiøse grupper som nekter blodoverføring og lærere er forpliktet på å fremme synspunkter som er i tråd med nyere vitenskapelige innsikter selv om det kan vekke anstøt i enkelte grupper. Et samfunn vil kunne holde seg med profesjoner og eksperter så lenge det er allment anerkjent at deres kunnskap har en høyere faglig kvalitet enn hvermannsens kunnskap.

Angsten for oppdragelse er like fullt en realitet, og den kan feste seg både kroppslig og mentalt hos profesjonsutøveren. Den kan melde seg som frykt for å bli beskyldt for rasisme, eller bare som en generell uro for å komme i skade for å tråkke noen på tærne. I et samfunn med stort mangfold er det vanskelig å vite hvor folk har sine ømme tær.

Generelt er tendensen at de som har en form for oppdrageransvar i samfunnet vegrer seg for å være normative, de tar ikke sjansen på å si hva som er bra å gjøre, men spesialiserer seg heller på detaljerte redegjørelser for hvordan det som er gitt å gjøre kan gjøres. Man blir instrumentell i sin kunnskapsutøvelse og styrer unna brede kontekstualiseringer. Man lar være å elaborere for mye, for i den utvida tilnærmingen, i den djerve kommunikasjonen som 
putter noen personlige vurderinger i sekken av fakta, ligger farene og lurer. Risikoen for a vekke til live heftige emosjoner er stor fordi man i sine personlige beskrivelser og vurderinger av et eller annet støter borti noe som andre mennesker verdsetter eller helligholder.

\section{Identitet som haute coture}

Profesjonsautoriteten blir stadig oftere utfordret ettersom identitetspolitikken blir mer og mer fremtredende i befolkningen. Av frykt for $\stackrel{\circ}{\mathrm{a}}$ ikke klare $\stackrel{\circ}{\mathrm{a}}$ balansere riktig i vrimmelen av rivaliserende identitetspretensjoner velger kanskje lærerne å skjerme bort lyset som kunne gjøre forståelseshorisonten deres synlig, de snurper sammen fantasien slik at det stort sett bare er fortolkninger og arbeidsbeskrivelser tilbake i deres kommunikative repertoar. Men som Susan Sontag skrev i 1961, blir prosjekter reaksjonære og kvelende når de blir redusert til å dreie seg om interpretasjoner. Joanna Williams (2016) reflekterer omkring Sontags påstand og poengterer at den logiske konsekvens av forsøket på å innfri alle slags krav med utspring i ulike identitetsprosjekter er en relativisme som undergraver basisen for å bedømme noen idéer som bedre enn andre. Resultatet blir i ytterste konsekvens et sammenbrudd for kommunikasjon, ja for selve aspirasjonen om å kommunisere, skriver Williams.

Respekten for identitetsmangfold kan paradoksalt nok resultere i konformisme. Bare dersom myndighetsutøveren er en svært modig person, slik som for eksempel lektor Simon Malkenes, kan den tendensen bremses. Malkenes deltok våren 2018 i en skoledebatt i Dagsnytt 18 hvor han samtidig ga noen eksempler på elevatferd i egen klasse i videregående skole. Noen elever mente seg krenket av måten de ble omtalt på (selv om ingen ble navngitt) og med assistanse fra folk i skolens ledelse skrev noen av dem et innlegg i Aftenposten. Rektor sendte også varsel til skoleeieren om saken, noe som innebærer at det kunne bli reist disiplinærsak mot Malkenes. Det skjedde ikke, men saken er en av flere som illustrerer risikoen som lærere Iøper i forsøk på uøve sin autoritet eller ved å fremme kontroversielle meninger.

De fleste lærere vil neppe ha det samme mot til å holde fast ved egne vurderinger som Malkenes. Det blir greiest å ikke fremme synspunkter som overskrider de rammene som læreplanen skisserer for det politisk korrekte. Noen lærere vil piske seg selv i retning av fakta og det «praktisk relevante» mens de føler på en dyp uro for at de, til tross for all forsiktighet, likevel risikerer å måtte stå til rette for noe. Plutselig kan det komme et spontant ord, en spontan vurdering, og læreren er på tynn is. Vurderinger er alltid emosjonelt ladet, og $i$ et mangfoldig, multikulturelt samfunn eller klasserom, kan enhver vurdering potensielt vekke anstøt.

\section{Profesjonsutøvere er fanget $\mathbf{i}$ en dobbel forpliktelse}

Profesjonsutøvere vil stadig komme i situasjoner der de risikerer å krenke noen når de tar beslutninger eller bare fremmer tydelige meninger. De som er lærere kan lett komme til å fornærme en elev eller en student i det flerkulturelle klassererommet. Men det kan like gjerne være at de bare engster seg for at en student har fordommer som han/hun ikke har. Resultatet kan uansett bli en inkorporert varsomhet hos læreren som kan lede til pedagogisk handlingslammelse. Vi får en forsiktighetens pedagog, en usikker og velvillig pedagog, som forsøker å legge til rette for det «minste felles multiplum» av virkelighetsforståelse i gruppen. Pedagogen framsnakker gjerne «positiv annerledeshet», men styrer unna forskjeller som ikke alle synes noe om.

Det er på ingen måte gitt at forsiktighetens pedagogikk gjør livet mer behagelig for læreren enn en pedagogikk med risiko. På den ene siden skal læreren gestalte fornuft og framskritt og forlange respekt for etablerte fakta og felles kjøreregler i samfunnet, på den annen side skal læreren gi spillerom for identitetsprosjekter som med utgangspunkt i kjønn, kultur, religion m.m. kan være på kollisjonskurs med det innholdet som de er faglig forpliktet på. Dette er en vanskelig balansegang. 
Det nye ubehaget har altså noe å gjøre med en dobbel forpliktelse som innebærer at profesjonsutøvere må forvalte både eksistenspolitikk og identitetspolitikk. Og særlig krevende er dreiningen i vår tid som har løftet identitetspolitikken foran eksistenspolitikken. Vår raison d'être har blitt det omvendte av Sartres berømte parole: eksistensen går forut for essensen (l'existence précède l'essence). No̊ har essensen blitt viktigere enn eksistensen; hvem man er teller mer enn hva man gjør. Den omsnudde Sartre må uvegerlig skape vansker for dem som har ansvar for oppdagelse i samfunnet. Utviklingen sporer også til ettertanke og uro blant oss som forsøker å fortolke det som skjer i samfunnet. Noen av oss spør seg om ikke identitetspolitikken har fătt et farlig stort spillerom. Thomas Hylland Eriksen (som for øvrig var rådgiver og inspirator ved etableringen av Flerkulturell forståelse som faglig satsingsområde ved Høgskolen i Oslo og Akershus på begynnelsen av 1990-tallet) har i dag følgende kommentar: «I en tid preget av identitetspolitikk, er det på tide med en aldri så liten eksistensialistisk renessanse» 1

Det ser ikke ut til at Hylland Eriksen vil få innfridd et slikt ønske. I mange av de kritiske konfrontasjoner som oppstår mellom kunnskap og identitet, mellom eksistens og essens, mellom fornuft og følelser, slåss et økende antall studenter og lærere for det sistnevnte. Et seminar arrangert av Fritt ord høsten 2016 hadde tittelen «Ytringsfrihet for fall i akademia». Der ble det løftet fram noen utviklingstrekk som gjelder flere steder i verden: På amerikanske universiteter senkes takhøyden, og sensur av pensum og forelesere sprer seg etter tallrike studentkampanjer. Universitetet i Cape Town i Sør Afrika kansellerte en forelesning av Flemming Rose fordi de var redd den kunne provosere. I Europa møter kravene om «traumevarsler» for kunst og pensumlitteratur økende støtte. Det argumenteres med at faglig innhold som kan virke støtende på enkelte studenter bør tas ut av undervisningen, fakta som presenteres bør være fritt for krenkende potensiale. $\AA$ verne om sårbare identiteter er viktigere enn å fremme ubekveme ideer.

Det mangler ikke på protester mot disse tendensene: I 2016 publiserte Kenan Malik på sitt nettsted Pandaemonium et innlegg med tittelen: «Academic freedom and academic cowardise» som svar på utestengingen av Flemming Rose fra Universitetet i Cape Town, Joanna Williams skrev boken Academic freedom in an Age of Conformity, og Mick Hume forsvarer kompromissløst ytringsfriheten i akademia i boken Trigger Warning: Is the Fear of Being Offensive Killling Free Speech. Den britiske sosiologen Frank Furedi (2017) følger opp og konkluderer med at det har skjedd en infantilisering av universitetet, studentene har blitt trygghetssøkende mer enn sannhetssøkende.

De nye trekkene i den globale utviklingen er oppsiktsvekkende. Det er veldig utypisk for studenter å kjempe for sensur av undervisningen. Den eneste sannsynlige forklaringen på fenomenet må nettopp være den historiske dreiningen jeg har påpekt, at identitetsfriheten nå har blitt viktigere enn idéfriheten. Opplysning og kunnskap har fallende status i verden. Idéer må oftere enn før vike når de er på kollisjonskurs med identiteter.

\section{Moralsk kulturrelativisme}

I våre utdanninger om flerkulturelle spørsmål ved OsloMet diskuteres ofte motsetningen mellom metodisk kulturrelativisme og moralsk kulturrelativisme. Den førstnevnte holdningen argumenterer for at man skal være åpen og lyttende til den andre, bestrebe seg så godt som mulig på å forstå de andre ut fra dennes egne premisser. Denne holdningen betyr ikke at man skal slutte å mene noe om den andres tro eller kultur, ei heller at en skal stille seg nøytral til eller gi avkall på egne verdier. Den moralske kulturrelativismen, derimot, propaganderer nettopp en avholdenhet når det gjelder vurderinger av andres kulturelle utrykk eller deres identifikasjoner. Det er denne moralske kulturrelativismen som har blitt ledetråd

\footnotetext{
1 Bokspalte i Morgenbladet, 18.01 - 24.012019 der Thomas Hylland Eriksen omtaler Sarah Bakewells bok At the Existentialist Café: Freedom, Being and Apricot Cocktails. London: Vintage 2016.
} 
for den nye identitetspolitikken som griper om seg i dag, og som insisterer på at «en person tilhørende en kategori bør ikke, eller kan ikke, uttale seg om erfaringene til en person fra en annen kategori» (Good, 2013). I sine ytterste konsekvens ødelegger moralsk kulturrelativisme frimodigheten til dyp og ærlig meningsutveksling mellom personer som tilhører ulike identitetsfellesskap; den utarmer det akademiske liv og bremser utviklingen i alle slags kunnskapsbaserte praksiser.

Det fremtredende standpunkt blant de moralske kulturrelativistene er en form for liberalisme som tolererer det meste fra den andre, og som stort sett lar den andre få holde på med sitt i fred så lenge det ikke går på bekostning av allmenne krav til borgerne i et samfunn eller kolliderer med menneskerettighetene. Det dreier seg om en forskjellstoleranse. Kritiske merknader til denne formen for toleranse dukker opp i faglitteraturen ${ }^{2}$. Kritikerne poengterer at det å tolerere forskjeller ikke er nok. De som tolereres behøver mer; de trenger empati, respekt og åpenhet. Nøkkelen er generøsitet, en vilje til å virkelig omfavne og lytte til «forskjellenes stemmer» (Wright, 2004). Kritikerne av liberal forskjellstoleranse hevder med andre ord at det er anerkjennelse og respekt folk egentlig ønsker seg, det holder ikke med passiv toleranse basert på kalkulasjoner av hva som rett og rimelig.

\section{Et ideologisk enfold bak forståelsen av mangfold?}

Under den omtalte dreiningen mot identitetspolitikk synes det å ligge en forestilling om at mennesker realiserer seg og sanker den viktigste anerkjennelsen i livet gjennom utfoldelse av personlig identitet. Svært mange oppdragere synes à ha alliert seg med forestillingen om at stor frihet for individuelle identitetsprosjekter vil gi den beste grobunn for utvikling av et menneske som medborger og for samfunnet som helhet. Men kanskje er dette et intellektuelt selvbedrag, en enfoldig idé om mangfold? Det er i alle fall rimelig grunn til å spørre om det nødvendigvis er tilfelle at det ligger en innfrielse av behovet for anerkjennelse i enden av et identitetsprosjekt? Blir folk for eksempel tilfredse i rollen som minoritet i samfunnet når deres identitet blir tolerert?

Noen vil påstå at identiteter er mer som umettelige gjøkunger: «The problem is that people are not totally satisfied when their lifestyles are tolerated. Being tolerated is like being ignored. So they will construct artificial identities for themselves" (Burms 1997). Problemet det pekes på her, er at den lunkne bekreftelsen som gis gjennom romslig toleranse for identitetsmangfold, ikke tilfører det enkelte menneske tilstrekkelig anerkjennelse, men like gjerne kan føre til abstinens og utløse impulser til å søke nye identitetsmarkører.

Vi trenger altså mer enn en høflig aksept før vi kjenner oss tilstrekkelig anerkjent. Vi vil være interessante, tiltrekkende, bli beundret osv., kort sagt være enestående. Folk ønsker ikke kun à bli tolerert: «They want to be found intriguing, interesting, fascinating or even intimidating» (Burms, 1997). Det å bli møtt med avsky kan endatil være mer tilfredsstillende enn avmålt aksept. Vi vil anerkjennes mer substansielt enn det som kommer av at livsformen vår gis muligheter for overlevelse.

Den rådende identitetspolitikken lider av en type historisk inkurie som likner den som ble Darwins utviklingslære til del. Darwin påpekte selv ved noen anledninger at artenes utvikling ikke bare dreier seg om et «naturlig utvalg» og «the survival of the fittest», men at det også handler om det Darwin kalte et «seksuelt utvalg». Ettertiden synes å ha glemt at artenes utvikling styres både av kampen for å overleve og kampen for å imponere. Påfuglhannen kan tjene som eksempel. Denne fuglen er ikke utrustet optimalt for overlevelse under vanskelige forhold, fordi den mangler den funksjonelle fysiske form som skulle tilsi rask flukt eller god kamuflasje i kampen for å overleve. Fjærdrakten og fargene gir imidlertid et stort fortrinn når

\footnotetext{
2 En slik kritikk møter for eksempel Brian Barry (2001). Culture and equality: An egalitarian critique of multiculturalism, Cambridge, Polity Press. Kritikerne poengterer at liberalere som Barry propaganderer en type toleranse som likner likegyldighet.
} 
det gjelder sex appeal, når det gjelder å imponere, være den utvalgte. Det sistnevnte aspektet ved utviklingslæren har langt på vei blitt neglisjert i tiden etter Darwin (Nørretranders, 2005). Noe tilsvarende synes å ha skjedd med våre forestillinger om anerkjennelse. Suksess for de som jobber med minoritetspolitikk i samfunnet har stort sett handlet om å få alle til å «klare seg». Vi verdsetter ståkarakterene og applauderer den som så vidt har berget seg. Vi har på ingen måte lagt like mye vekt på å støtte opp om trangen til å briljere og utmerke seg.

Det offentliges støtte til identitetspolitikk er støtte til overlevelsespolitikk, det er et bidrag til at alle skal kunne stabilisere et liv i trygge omgivelser litt over bunnlinja. Tanken er at «alle skal med», og det bekymrer lite at det kanskje er de samme menneskene som har ståplass bakerst hele tiden. På overflaten kan det se ut som en flokk, som et «vi». Under overflaten er det mange av de tilstedeværende som er frafalne.

Det er neppe mulig å tildele folk nok anerkjennelse selv ved fremragende praktisering av toleranse. Det sniker seg alltid inn en ubevisst rangering, en dose nedlatenhet, i utøvelsen av tolerant identitetspolitikk. Dette er uunngåelig, for identitetspolitikken er i sin natur rangering og diskriminering. Som Gregory Bateson skal ha sagt det: Every codification is also an evaluation. Selv om vi løfter identitetstoleransens og den formelle likestillingens fane høyt, kan det aldri lykkes oss å desinfisere kommunikasjonen vår slik at alle spor av fordommer og rasisme blir borte: «The potential to say a racist thing or think a racist thought resides in all of us like an unearthed mine from a forgotten war», skriver Claudia Rankine i prosadiktet Medborgar (2018).

Reduksjon av ulikhet er ikke tilstrekkelig for frihet, og toleranse er ingen fullgod erstatning for anerkjennelse. Eksperter på HR som forsøker å skolere medarbeidere i et arbeidsfellesskap til aldri å krenke noen vil ikke kunne lykkes. Toleransens kjølige forsiktighet kan aldri få bukt med all diskriminering og rasisme, og det minesveipende blikket hos pedagoger og andre profesjonsutøverne kan aldri oppdage og avinstallere all potensielt krenkende kommunikasjon.

\section{Anerkjennelsen må omfatte subjektivitet}

I sin nyeste bok Identity: Contemporary Identity Politics and the Struggle for Recognition: The Demand for Dignity and the Politics of Resentment (2018) framholder den amerikanske statsviteren Francis Fukuyama at der er jakten på anerkjennelse som driver identitetspolitikken, men det som i utgangspunktet er et gode for mennesker truer nå demokrati og samhold i samfunnet. Fukuyama frykter at de brede felles identitetene er i ferd med $a ̊$ erodere i kjølvannet av en aggressiv identitetspolitikk fra et økende antall minoritetsgrupper.

Kampen for gruppeidentiteter er en kamp med tveegget sverd. Identiteten det kjempes for kan fort bli til en «identitet som dreper», advarer forfatteren Amin Malouf (2003). Han peker på linjene som går fra identitetspolitikk til sinne og hatkommunikasjon. Og er kanskje disse linjene ekstra tydelige der bakerst i køen hvor mennesker forvalter sin gruppeidentitet og ikke øyner mulighet for noe nytt og mer nyttig? Er det ikke nettopp i slike situasjoner at identitet blir farlig, når folk ikke lenger ser noen mulighet for en gang å kunne stå på toppen av pallen, være enestående individer - når folk begynner å gå i ett med sine kulturelle omgivelsene, vernefarget og anonyme i sin tilordning til en gruppe?

Den nederlandske pedagogen Gert Biesta (2014) hevder at først når kravet om å få være subjekt i verden innfris kan et menneske få tilfredsstilt sitt hele behov for anerkjennelse. Biesta støtter seg til filosofen Levinas og skriver at mennesket har behov for å erfare seg selv som «enestående», og at det da slett ikke dreier seg om essens eller identitet. Hvis vi satser på identitet når vi skal uttrykke vår eneståenhet, gjelder det eneståenhet som annerledeshet. Det som virkelig gir eksistensiell tilfredshet er imidlertid ikke annerledeshet, mener Biesta, men uerstattelighet. Det å kunne være et uforlignelig subjekt i verden. 
Subjektivitet er imidlertid fundamentalt annerledes som livsprosjekt enn identitet. Subjektivitet er nemlig ikke noe en har konstant, som en essens, men noe som forekommer som hendelser. Subjektivitet innebærer personlige handlingsvalg, og uten risiko i livet realiseres ingen subjektivitet, poengterer Biesta. Forskansning i trygge identiteter kan ikke åpne for subjektivitetshendelser. Subjektivering, når det skjer, er samtidig des-identifikasjon, subjektivitetshendelser er følgelig bevegelser bort fra identitetspolitikken. A lene seg for mye på identitet ødelegger samtidig for muligheten til å være subjekt i verden.

\section{Oppsummering}

En sunn og tilfreds medborger må først og fremst kunne realisere seg som fritt og stridende subjekt, ikke som identitetstynget og fredet objekt. Om det er subjektivitetsprosjekter som skal til og ikke identitetsprosjekter, i så fall kreves det en annen idé om oppdragelse enn den engstelige versjonen som Foros og Vetlesen skriver om.

Det burde nå være tydelig at identitetsprosjekter ikke har potensiale til å gi et menneske en solid følelse av å være anerkjent uansett hvor mye de tolereres eller applauderes. Toleranse synes i mange tilfelle å svekke effekten av de forskjellene som tidligere har tjent som identitetsmarkører og utløser jakt på nye og mer presise distinksjoner.

En hypotese kan være at så lenge det ikke gis spillerom for menneskers subjektivitet, vil jakten på nye identitetsmarkører ikke få noen ende. Identitetsprosjektene blir bare mer og mer mangfoldige, raffinerte og eksklusive. Det omvendte skjer når subjektivitet prioriteres: Identitetsprosjektene blir mindre raffinerte og relasjonene til medmennesker på tvers av tilhørigheter blir mer raffinerte. Menneskerettene vil da på ny vekke interesse og engasjement. Det å kreve like rettigheter for alle gruppeidentiteter skyver tanken om det menneskelige per se, menneskerettene, i bakgrunnen. Verdier som empati, respekt og åpenhet ignoreres (Wright, 2004).

Dette lille essay bærer fram en refleksjon om identitetspolitikkens skyggesider, først og fremst det at identitetspolitikken har blitt for dominerende, at identitetsprosjektene har blitt for viktige. I et samfunn som er bygget på opplysningstidens idealer, hører vi nå stadig oftere at idéer er farlige. Det forlanges at sårbare identiteter bør skånes mot ubehagelige fakta, «fake news» kan derfor være å foretrekke framfor ubehagelige nyheter. En slik holdning er bare forståelig i lys av den generelle ideologiske vending der essensen teller mer enn eksistensen, der identitet har blitt viktigere enn subjektivitet. Som Thomas Hylland Eriksen anbefaler, trenger vi nå en tilbakevending: eksistensen må gå forut for essensen, idéer må telle mer enn identiteter. Dette er avgjørende for all kunnskapsutvikling. For idéer lar seg kritisere, identiteter lar seg bare krenke. 


\section{Referanser}

Barry, Brian (1997). Liberalism and Multiculturalism. Ethical Perspectives 4 (1997) 2, p.3.

Barry, Brian (2001). Culture and equality: An egalitarian critique of multiculturalism. Cambridge: Polity Press.

Biesta, Gert (2014). Utdanningens vidunderlige risiko. Bergen: Fagbokforlaget.

Burms, Arnold (1997). Critical Remarks. Some remarks about Brian Barry's paper Liberalism and Multiculturalism. Ethical perspectives 4 (1997)2, p.12.

Dalrymple, Theodor (2001) Life at the Bottom: The Worldview That makes the Underclass. Chicago: Ivan R. Dee Publisher.

Foros, Bjørn og Vetlesen, Arne Johan (2012). Angsten for oppdragelse. Et samfunnsetiske perspektiv på dannelse. Oslo: Universitetsforlaget.

Fukuyama, Francis (2018). Identity: Contemporary Identity Politics and the Struggle for Recognition. London: Profile Books Ltd.

Furedi, Frank (2017). What's Happened To The University? A sociological exploration of it's infantilisation. London: Routledge.

Good, Graham (2013). Identity politics is killing college life. Spiked 23. sept. 2013 (www.spiked-online).

Hume, Mick (2016).Trigger Warning: Is the Fear of Being Offensive Killing Free Speech? William Collins /Harper Collins Publisher.

Malik Kenan (2016). Academic freedom and academic cowardice. Pandaemonium (22. juli 2016). Kenanmalic.com.

Malouf, Amin (2003). Identitet som dreper. Oslo: Pax forlag.

Nørretranders, Tor (2005). Det generøse menneske. En naturhistorie om at umak gir make. Oslo: Aschehoug.

Rankine, Claudia (2018). Medborgar. Eit amerikansk dikt. Oslo: Det norske samlaget.

Williams, Joanna (2016). Academic Freedom in an Age of Conformity. Confronting the Fear of Knowledge. Palgrave Macmillan.

https://doi.org/10.1057/9781137514790

Wright, Andrew (2004). The politics of Multiculturalism. A review of Brian Barry, 2001. Culture and equality: An egalitarian critique of multiculturalism, Cambridge: Polity Press. 